\title{
The Phonetics And Phonology of Rhotics IN MODERN IRISH
}

\author{
CORMAC ANDERSON, SYLWESTER JAWORSKI
}

\section{Introduction}

This paper examines the phonology and phonetics of rhotics in Modern Irish. Descriptions of the Old Irish language posit four distinct rhotic phonemes, differentiated along the axes fortis-lenis and broad-slender, the same oppositions being relevant also for laterals and coronal nasals. However, descriptions of modern Goidelic dialects typically posit two or three distinct rhotic phenomes. While the distribution and nature of sonorant contrasts has featured strongly in discussions about sound change and phonological patterning in the Insular Celtic languages, there has been little empirical study into the synchronic status of sonorants in contemporary Irish, a point this paper aims to address.

Rhotics in general are a somewhat amorphous class as there is no one acoustic feature that is found in all rhotics (see Lindau 1985, Ladefoged \& Maddieson 1996). Palatalised rhotics are particularly interesting, as, although they are something of a rarity cross-linguistically, they are found in both Irish and in many Slavic languages, including Russian, Bulgarian, Ukrainian, Upper and Lower Sorbian, making them a fitting object of enquiry for a volume dedicated to the relationship between the Celtic and Slavic languages. Żygis (2005) argues that palatalised rhotics, especially trills, are marked segments because they are (1) less frequent than their unpalatalised counterparts, (2) more complex in terms of articulation, (3) perceptually less salient, (4) acquired later in the acquisition process, (5) phonetically unstable, and (6) more narrowly distributed. Although the current investigation concentrates on rhotics in Irish, comparative reference to Slavic languages is made where appropriate.

The paper is structured as follows. Section 2 outlines the phonological system of Modern Irish and discusses the treatment of sonorant consonants, and rhotics in particular, in historical studies of the Goidelic languages and dialect descriptions of Irish and Scottish Gaelic. Section 3 introduces the data collection methods of the current study, which include both a phonetic experiment involving two native speakers of Connemara Irish and frequency data gleaned from a number of specially chosen corpora. Section 4 discusses the phonetics of rhotics in general and their frequency in Modern Irish, while Section 5 concentrates on initial rhotics, Section 6 on final rhotics and Section 7 on rhotics in clusters. Section 8 makes some concluding remarks. 


\section{Rhotics in Irish phonology}

\subsection{Principal features of Irish phonology}

The phonological word in the Irish language is defined by a lexical nucleus, with either nominal or verbal force, typically carrying strong initial stress. ${ }^{1}$ This nucleus may be supplemented by unstressed proclitics, known as iarmbéarla in Classical Irish grammar (see Bergin 1916-55; Adams 1970), and unstressed postclitics, known as barr. The initial of the lexical nucleus, that is the primary stress position, is subject to alternation between radical segments and lenited ones, the latter being triggered by a morphosyntactic proclitic, which may be covert in Modern Irish. ${ }^{2}$ Initial obstruents show a further alternation with a homorganic obstruent or nasal segment, in this case always following an overt proclitic trigger. These alternations are collectively termed mutations, the first being known as lenition, the second as eclipsis.

In word-initial position, a useful distinction can thus be made between those consonants which occur radically and those which can only surface under mutation, while the term 'mutation trajectories' defines the various alternations undergone by particular radical consonants. The following table sets out the mutation trajectories of Old Irish radicals.

\begin{tabular}{|l|l|l|l|l|l|l|l|l|l|l|l|l|}
\hline Radical & $\mathrm{p}$ & $\mathrm{t}$ & $\mathrm{k}$ & $\mathrm{f}$ & $\mathrm{b}$ & $\mathrm{d}$ & $\mathrm{g}$ & $\mathrm{m}$ & $\mathrm{s}$ & $\mathrm{N}$ & $\mathrm{L}$ & $\mathrm{R}$ \\
\hline Lenited & $\varphi$ & $\theta$ & $\mathrm{x}$ & $\varnothing$ & $\beta$ & ə & $\gamma$ & $\mu^{3}$ & $\mathrm{~h}$ & $\mathrm{n}$ & 1 & $\mathrm{r}$ \\
\hline Eclipsed & $\mathrm{b}$ & $\mathrm{d}$ & $\mathrm{g}$ & $\beta$ & $\mathrm{m}$ & $\mathrm{N}$ & $\mathrm{y}$ & - & - & - & - & - \\
\hline
\end{tabular}

Table 1. Old Irish consonant phonemes and mutation trajectories.

As can be adduced from Table 1 above, obstruents and nasals are defined for one of three degrees of localisation, which may be referred to in articulatory terms as labial, coronal and velar. The coronal fricatives $/ \theta \partial /$ were lost in the transition to Modern Irish, being replaced instead by $/ \mathrm{h} \gamma /$. Obstruents show a

\footnotetext{
${ }^{1}$ This statement holds true for older varieties of the Irish language and in general for Northern and Western dialects. In Munster Irish however, stress may shift on to a subsequent syllable under certain conditions (see Gussmann 1997 for discussion).

${ }^{2}$ The term 'incorporated', is used by some scholars (Oftedal 1962; Ternes 1990; Iosad 2010) to define those cases where mutation occurs without an overt trigger. An example is the past tense in most dialects of Modern Irish, which is lenited even when there is no surface preclitic, e.g. chuir sé 'he put', from the verbal root (imperative) cuir.

${ }^{3}$ This paper follows the convention in Celtic linguisitics of transcribing the labial nasalised continuant that results from the lenition of $/ \mathrm{m} /$ as $/ \mu /$, whereas $/ \tilde{\beta} /$ would be more faithful to the IPA. Analagously among the sonorants, majuscule /N L R/ are used for the fortis sonorants and minuscule $/ \mathrm{n} 1 \mathrm{r} /$ for lenis sonorants. The use of Latin rather than Greek type for $/ \mathrm{f} /$ is a transcriptional convenience, as this segment is held to be bilabial $[\varphi]$ in Old Irish, as it is also in dialect descriptions of twentieth century Modern Irish dialects (Ó Cuív 1944: 40-1; de Bhaldraithe 1945: 31-2; Breatnach 1947: 37; de Búrca 1958: 29-30; Mhac an Fhailigh 1968: 32).
} 
distinction between those which are typically aspirated and those which are not aspirated but may be passively voiced. In this sense, Irish is typologically more similar to Germanic languages than to Romance or Slavic ones. This distinction may be captured privatively, considering the aspirated series to be characterised by a privative phonological feature, e.g. [spread glottis] (Iverson \& Salmons 1995; Kehrein 2001) ${ }^{4}$ or element, e.g. $|\mathrm{H}|$ (Cyran 1997, BlochRozmiej 1998, Jaskuła 2006), that the unaspirated series lacks. Unlike Modern English or German, this analysis is supported by consonant frequency data in Modern Irish (Anderson 2012: 20).

Further to these distinctions, all consonants, with the possible exception of $/ \mathrm{h} /$ in some analyses, are specified as either leathan 'broad' or caol 'slender'. ${ }^{5}$ Articulatory terminology does not capture this distinction well, ${ }^{6}$ but it may be observed that the broad series, transcribed without diacritic $/ \mathrm{C} /$, often have a velar secondary articulation and the slender series, transcribed with a postposed prime $/ \mathrm{C}^{\prime} /$, a palatal secondary articulation. In the absence of satisfactory alternatives, the traditional terminology, in English translation, is retained in this paper. The actual phonetics of the broad-slender opposition, as it applies to rhotics, is a key object of enquiry in the current study.

Modern Irish dialects have minimally the long vowels /i: e: a: o: u:/, the centralising diphthongs /iə/ and /uə/ and the falling diphthongs /ai/ and /au/. Unstressed short vowels do not contrast at all, and may thus be transcribed /ə/, although their phonetic quality varies greatly due to contextual factors. In positions of primary stress, five or six phonemic short vowels are listed in the traditional dialect studies (e.g. Mhac an Fhailigh 1968: 10-19), but substantial allophony was already recognised by de Búrca (1958: 8-9). The gravity of a given stressed short vowel segment is entirely predictable by the quality (broad or slender) of surrounding consonants, leaving only saturation as contrastive in the short vowel system.

While this analysis is in essence structuralist - the recognition of combinatory variation in a phonological subsystem - it is generally scholars in the generativist tradition who operate under the assumption of a three-member vertical short vowel system in Modern Irish. The general workings of this system are outlined in Ó Siadhail and Wigger (1972) and Ó Siadhail (1989: 35-6)), and are adapted to the formalism of Feature Geometry by Ní Chiosáin (1994) and Government Phonology by Cyran (2002: 35-9). Anderson (2014) extends the analysis of a vertical short vowel system to the Old Irish period.

\footnotetext{
${ }^{4}$ This approach is known as laryngeal realism and builds on earlier work on the typology of laryngeal contrasts, e.g. Lisker \& Abramson (1964) and Kim (1970).

${ }^{5}$ Some scholars (Vendryes 1908; Thurneysen 1909; 1946; Pokorny 1913; Anderson 2014) posit three consonant qualities rather than two for the Old Irish period.

${ }^{6}$ Gleasure (1968) gives a good overview of the terminological issues involved with respect to this issue.
} 
The phonemic transcription of this paper, indicated by slanted brackets, assumes this three-member vertical short vowel system, transcribed high $/ \mathbf{i} /{ }^{7}$ mid /a/ and low /a/.

\subsection{Rhotics in Irish phonology}

A potential issue for the vertical vowel analysis is that the traditional dialect studies agree that the broad-slender distinction is neutralised in favour of the broad member of the opposition in absolute anlaut (Ó Cuív 1944: 50; de Bhaldraithe 1945: 42; Mhac an Fhailigh 1968: 44, 163). This fact is surprising in view of the fact that this position is generally assumed to be the least likely place for phonetic weakening or neutralisation to occur, perhaps especially so in a language such as Irish, where consonant mutation renders the initial position of great morphological importance. The issue of word-initial rhotic neutralisation is that vowel gravity must be considered phonemic if there is no initial slender rhotic. The vertical vowel analysis relies on phonemicisations such as reic 'sale' $/ \mathrm{r}^{\prime} \partial \mathrm{c}$ '/ versus roc 'wrinkle' $/ \mathrm{r} ə \mathrm{c} /$, but if the slender rhotic cannot be said to occur initially, then the only possibility is to phonemicise as $/ \mathrm{rec}^{\prime} /$ and $/ \mathrm{roc} /$ respectively. The phonetics and phonology of the broad-slender distinction in initial rhotics is examined in detail in Section 5 below.

The consonants given in Table 1 above are also contrastive outside of initial position, which means that they must all be considered phonemic. Most scholars (Thurneysen 1909; 1946; Pokorny 1913; McCone 2005) posit four coronal nasals, four laterals and four rhotics for Old Irish, the relevant oppositions being fortis-lenis and broad-slender. The terms fortis and lenis are phonetically inexact, and have been used in many different ways in the phonological literature (Ladefoged \& Maddieson 1996: 95), but are retained here for convenience.

A full four-way distinction in all sonorants no longer exists in any variety of Goidelic. Many Scottish Gaelic dialects have developed a three-way distinction in sonorants, which may be called broad, plain and slender. ${ }^{8}$ In Irish, Ulster (northern) varieties have maintained the four-way distinction for the nasals and laterals (Quiggin 1906; Wagner 1959) or have innovated in a similar way to Scottish Gaelic. On the other hand, Munster (southern) varieties have lost the fortis-lenis distinction for all sonorants, with compensatory lengthening before historically fortis segments. The Connacht (western) varieties tend to be intermediate between the two poles. The four-way distinction in the rhotics survives nowhere, and most analyses do not consider

\footnotetext{
${ }^{7}$ This symbol is preferred to Ó Siadhail's / $w /$ because it denotes a central rather than back vowel in the IPA, thus being a more suitable transcription for a vowel phoneme unspecified for gravity.

${ }^{8}$ Ternes (1972: 22-31) examines a typical case of a three-way distinction in a Scottish Gaelic dialect and discusses the historical developments.
} 
the fortis-lenis distinction as existing in the contemporary varieties of Connacht and Munster. The issue of the historical fortis-lenis distinction and its loss is discussed as part of Section 6, which deals with rhotics in final position.

The fortis-lenis distinction in sonorants is also held to be contextual to an extent, with neutralisation in favour of the fortis segments in sonorant plus obstruent clusters (i.e. RT-clusters) and in favour of the lenis segment in obstruent plus sonorant clusters (i.e. TR-clusters) in the most influential traditional analysis (Thurneysen 1946: 74). This status of sonorants in RTclusters in particular has been central to discussions of historical sound change in the Insular Celtic languages (e.g Sommerfelt 1954, Jackson 1960). This question is taken up further in the discussion of rhotics in clusters in Section 7.

\section{Data collection}

\subsection{Phonetic experiment}

In order to investigate the status of rhotic consonants in Modern Irish, two native speakers of Connemara Irish were asked to take part in the experiment. Speaker P, in his seventies, is a native of Galway city but resident in Germany for the last fifty years. Speaker M, in his fifties, was born and still lives in Connemara. Both speakers are well-educated and are also fluent speakers of English.

To collect the data, both informants read a list of words twice. First, they read the target words in isolation and then they read the same vocabulary items embedded in the carrier phrase Scriobh an múinteoir $X$ ar an mbord 'The teacher wrote $\mathrm{X}$ on the board'. The rationale behind this procedure was to examine the existence of phonological contrasts in citation forms, not only when the items were produced in isolation but also in connected speech. Importantly, the list of target words contains a number of near minimal pairs in which both rhotics immediately followed the same vowel, e.g. féar and aréir. Following other researchers (cf. Ladefoged \& Maddieson 1996), we measured the F1 values of vowels preceding predicted broad and slender rhotics in order to ascertain their status. Since neither of the reading conditions involved fast speech, the formants were measured in the middle of the steady state, i.e. the part of a vowel during which the formants are constant. ${ }^{9}$ Once the F1 values of vowels preceding predicted broad and slender rhotic sounds were measured, a T-test for independent samples was applied to ascertain whether the differences in formant frequencies of the vowels reached the level of statistical significance.

\footnotetext{
${ }^{9}$ The Praat software (version 4.2.21) was used to digitise the data, perform the acoustic analyses as well as produce the spectrograms included in the following section.
} 
Our data include rhotic sounds placed in the following contexts: (1) intervocalic, e.g. cara, doras (included in the general discussion of rhotics in Section 4); (2) word-initial, e.g. roth, rith (explored further in Section 5); (3) word-final, e.g. féar, aréir (dealt with in Section 6); (4) initial clusters with rhotic in post-consonantal position, e.g. bróg, trí, and (5) final clusters with rhotic in pre-consonantal position, e.g. cairt, ceart (both considered in Section 7).

\subsection{Corpora}

General data on rhotic frequency, and on the relative frequency of broad and slender consonants, is drawn from the only two published papers of which we are aware that examine Irish phoneme frequency, de Búrca (1960) and Anderson (2012). The former analysed the relative frequency of 1,000 phonemes drawn from a list of discrete words, based on his own dialect study of Tourmakeady Irish (de Búrca 1958). The latter drew its data from a connected text corpus based on a phonemicisation of the Constitution of Ireland (Bunreacht na hÉireann, henceforth 'BÉ'). Data from the latter corpus has been included which did not appear in Anderson (2012).

For the section on initial rhotics, additional data was collected by counting headwords in the Dictionary of the Irish Language (Quin et al. eds. 2007; henceforth 'DIL') and in the Collins Gem Irish Dictionary (Mac Mathúna \& Ó Corráin 1995; henceforth 'CD'). For the section on final rhotics, use was made of the Reverse Dictionary of Modern Irish (Doyle \& Gussmann 2004; hereinafter 'RD'). It must be stressed the frequency data from all four of our corpora (BÉ, DIL, CD, RD) are not strictly comparable. BÉ is a continuous legal text, while the other three are treated here as lists of discrete words. Furthermore, DIL primarily addresses Old and Middle Irish, whereas $\mathrm{CD}$ is designed for learners of colloquial Modern Irish. As RD is a reverse dictionary, and thus useful only for final position, it is nowhere comparable with results from DIL or CD. It is to be hoped that the results from this data collection may help to spur future research into the frequency and distribution of sounds at all stages of the Irish language.

\section{General remarks on Modern Irish rhotics}

\subsection{Frequency and articulation of rhotics}

Both de Búrca (1960) and Anderson (2012) agree that rhotics are of very high frequency in Modern Irish: 15.8\% of consonants in the former and 14\% in the latter are rhotics. As regards the proportion of rhotics which are broad or slender the two studies differ somewhat: in de Búrca $65.3 \%$ of rhotics are broad, in Anderson only 57.9\%. This is paralleled to an extent in the results the two studies obtained with respect to the prevalence of consonant quality in general: in de Búrca $66.6 \%$ of consonants are broad, in Anderson only $61.7 \%$. 
In spite of this variation, which may be attributable to differences in methodology, the two studies agree that both broad and slender rhotic phonemes are among the most frequent segments in Modern Irish. In de Búrca (1960) the broad rhotic is the most frequent consonant phoneme in the language (10.3\% of all consonants) and the slender one the fourth (5.6\% of all consonants). In Anderson (2012) the broad rhotic is the second most frequent consonant phoneme (7.9\%) and the slender one the fourth $(6.1 \%)$. These results are somewhat surprising, given the cross-lingusitic tendency of rhotics to weaken and the reputation of palatalised rhotics as being particularly marked segments (Żygis 2005).

From an articulatory perspective, there was substantial variation in the characteristics of the rhotic sounds of our two informants. Although rhotics are often assumed to be trills, trilled variants are rather rare in the data. Considerable differences could also be observed between the two informants: Speaker M did not produce any trills, whereas in P's performance, trilled variants constitute as many as $22.5 \%$ of tokens. Both participants regularly reduce the $\langle\mathrm{r}\rangle$ sounds to approximants; however, many more approximants are found in M's speech (62.5\%), almost twice as many as in the data produced by Speaker P (33.75\%). As for fricated variants, approximately one third of all tokens underwent frication and both subjects produced similar results, $32.5 \%$ and $27.5 \%$ respectively. Needless to say, palatalised rhotics are much more susceptible to frication as the raised dorsum narrows the channel through which the airstream passes, thus creating aerodynamic conditions conducive to friction. Finally, the data also include a number of tapped variants. Predictably, more taps (approximately 15\%) can be found in Speaker P's performance, as he also produced a number of trills. By comparison, in M's speech, only $4.5 \%$ of rhotic tokens were taps.

\subsection{Voiceless rhotics}

In a number of the dialect studies (e.g. de Bhaldraithe 1945: 42), voiceless rhotics are posited as distinct phonemes, occurring when the rhotic is adjacent to $/ \mathrm{h} /$, which results from lenition of $/ \mathrm{t} \mathrm{t}^{\prime} \mathrm{s} \mathrm{s}^{\prime} /$ and in future and conditional verbal forms exhibiting orthographic $\langle\mathrm{f}\rangle$. In BÉ there were 118 combinations of rhotics and $/ \mathrm{h} /, 57$ of them broad and 61 of them slender. This combined total for the putative voiceless rhotics makes up $0.4 \%$ of the entire consonant sample, comparable to the frequency of $/ \mathrm{p} \mathrm{p}^{\prime} /$ (125 tokens) and considerably greater than that of than $/ \mathrm{y}^{\prime} /$ ( 66 tokens or $0.2 \%$ ).

However, there are a number of phonological reasons to favour a cluster analysis for combinations of rhotics adjacent to $/ \mathrm{h} /$. Following such an analysis, lenition of $/ \mathrm{t} \mathrm{s} /$ to $/ \mathrm{h} / \mathrm{has}$ a parallel in lenition of $/ \mathrm{tr} \mathrm{sr} / \mathrm{to} / \mathrm{hr} /$, without having to posit a separate lenition of / $\mathrm{tr} \mathrm{sr} /$ to $/ \mathrm{r} /$ as one would if the voiceless rhotics are considered distinct unit phonemes. Although rhotics in this environment 
were only partially voiced in the speech of our two informants, they were also clearly preceded by [h]. One such case is presented in Figure 1, which depicts a spectrogram of shroich pronounced in connected speech by Speaker M. It is evident from the diagram that the voiceless rhotic is made up of two distinct elements: (1) a voiceless fricative [h], and (2) a rhotic approximant that is only partially voiced. In the spectrogram, the voiced part of the rhotic is represented by the onset of voicing (approximately $10 \mathrm{~ms}$.).

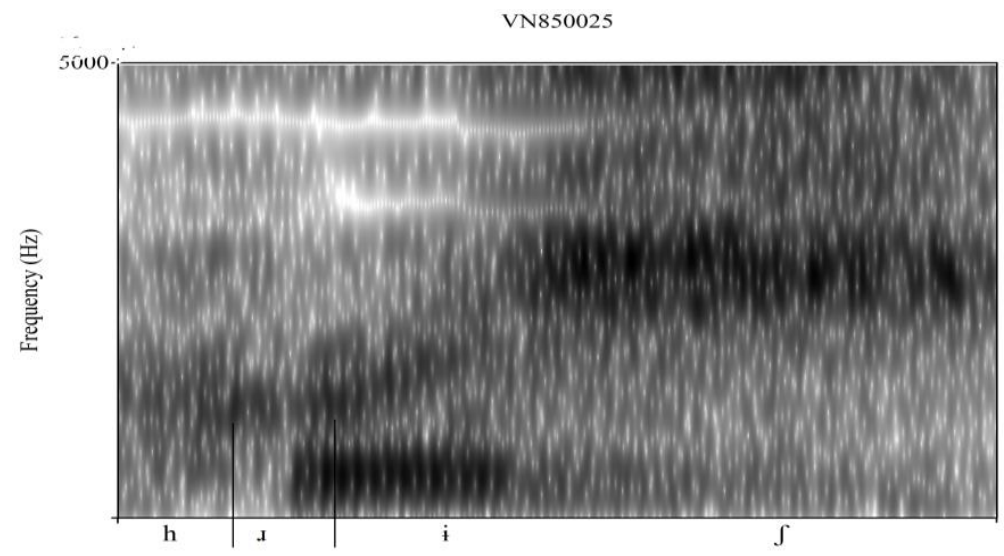

Figure 1. A partially voiced rhotic in shroich.

\section{Word-initial rhotics}

Although in Irish rhotic consonants high frequency sounds, as outlined above, the data suggests that absolute anlaut is not a preferred position for rhotic consonants. Of 27,632 headwords beginning with a singleton initial consonant in DIL, only $4.7 \%$ were rhotics, roughly a third of the proportion of rhotic consonants in all positions in the studies of de Búrca (1958) and Anderson (2012). This anomaly is substantiated by BÉ, where the proportion of rhotic consonants that occur in initial position extraordinarily low, at only $8.9 \%$ of all rhotics. For all other consonants the proportion of initials is above $20 \%$ and averages at $29.9 \%$ over the entire sample.

Although the broad-slender distinction in rhotics is considered to be neutralised in initial position in traditional dialect descriptions of the Irish language, we examined the relative frequency of initial rhotics before broad and slender vowels in our corpora. Of 27,632 headwords with singleton initial consonants in DIL, $37.4 \%$ are slender, with a similar figure of $39.3 \%$ from the 8,896 initial singletons in BÉ. These figures are broadly comparable to the overall relative frequency of slender consonants in Modern Irish, which is $33.4 \%$ in de Búrca (1960) and 36.7\% in Anderson (2012). These results are to be 
welcomed, because they suggest that $35-40 \%$ is likely to be a good estimate of the proportion of slender consonants at all stages of the language.

However, there is striking variation in DIL when the relative frequency of the broad-slender distinction for each consonant pair in initial position is taken into account, ranging from $57.8 \%$ slender in the case of $/ \mathrm{s} \mathrm{s}^{\prime} /$ to only $17.9 \%$ slender in the case of $/ \mathrm{k} \mathrm{k}^{\prime} /$. The proportion of slender $/ \mathrm{r}^{\prime} /$ as compared to broad $/ \mathrm{r} /$ is towards the higher end of this range, at $47.1 \%$ of 1,030 headwords. This figure is strongly supported by $\mathrm{CD}$, in which $47.2 \%$ of 439 tokens are slender. The figure from BE is even higher, at $70.2 \%$ of 389 tokens.

In the speech of both our informants $/ \mathrm{r} /$ and $/ \mathrm{r}^{\prime} /$ are definitely distinct when found in word initial position, but only when they are followed by a long high front vowel. This finding is hardly surprising, given that [i]-adjacent consonants undergo palatalisation in all languages. However, in other phonological contexts, including the mid front [e:], the two rhotics seem to have merged. Predictably, it is the plain sound that is found in the nonpalatalising environments. The data also revealed that the informants realise the initial ' $r$ ' sounds as approximants in both environments. As a matter of fact, neither of the speakers made a single word-initial trill, which is indicative of the weakness of Irish rhotics initially. The rhotics before slender vowels were more often approximants than those before broad ones.

\section{Word-final rhotics}

Final position is the most common position for Irish rhotics, with $31.6 \%$ of all rhotics in BÉ occurring in absolute auslaut. In this position the broad member of the opposition (72.1\%) is considerably more frequent than the slender one (27.9\%). Consonant quality in final position helps to distinguish morphological forms, as many masculine nouns have a nominative singular ending in a broad consonant and a genitive singular and nominative plural ending in a slender one, e.g. cat 'cat' $/ \mathrm{kat} / \mathrm{with}$ genitive singular and nominative plural cait $/ \mathrm{kat}^{\prime} /$. We are not aware of any study examining the relative frequency of different case forms in Modern Irish, but classical studies of frequency and markedness (e.g. Greenberg 1966) suggest that categories of nominative and singular are cross-linguistically more common than oblique cases or non-singular number.

A further explanation for the high frequency of final /r/ in BÉ is the fact that it occurs in the word $\operatorname{ar}$ (318 of 997 occurrences of final $/ \mathrm{r} /$ or $31.9 \%$ ). This particular word is polysemous, being either a preposition, with the approximate meaning 'on', or a proclitic past tense relative or interrogative marker. In both the latter cases it is an iarmbéarla, occurring before primary stress and is thus subject to a range of assimilation and elision effects in many dialects of Modern Irish. 
As regards the status of broad and slender rhotics in final position in the speech of our two informants, differences were observed between the two speakers. Speaker M maintains the contrast in words pronounced in isolation and, to a lesser extent, in connected speech, whereas in the case of Speaker P, who no longer lives in Ireland, the rhotics appear to have merged. For instance, in the near-minimal pair féar and aréir, the word-final rhotic is supposed to be broad in the former, whereas in the latter token slender [ $\left.\mathrm{r}^{\prime}\right]$ is predicted. If that is the case, then the F1 parameter of the vowel [e:] in féar should be higher than that in aréir. ${ }^{10}$ This prediction is confirmed by the data produced by speaker $\mathrm{P}$ in the words pronounced in isolation. As the two spectrograms in Figure 2 show, the average value of the first formant of [e:] in aréir $(454 \mathrm{~Hz})$ is, in fact, almost $50 \mathrm{~Hz}$ lower than that of the same vowel in féar $(497 \mathrm{~Hz})$, which strongly suggests that the speaker did produce a palatalised rhotic in the latter word.

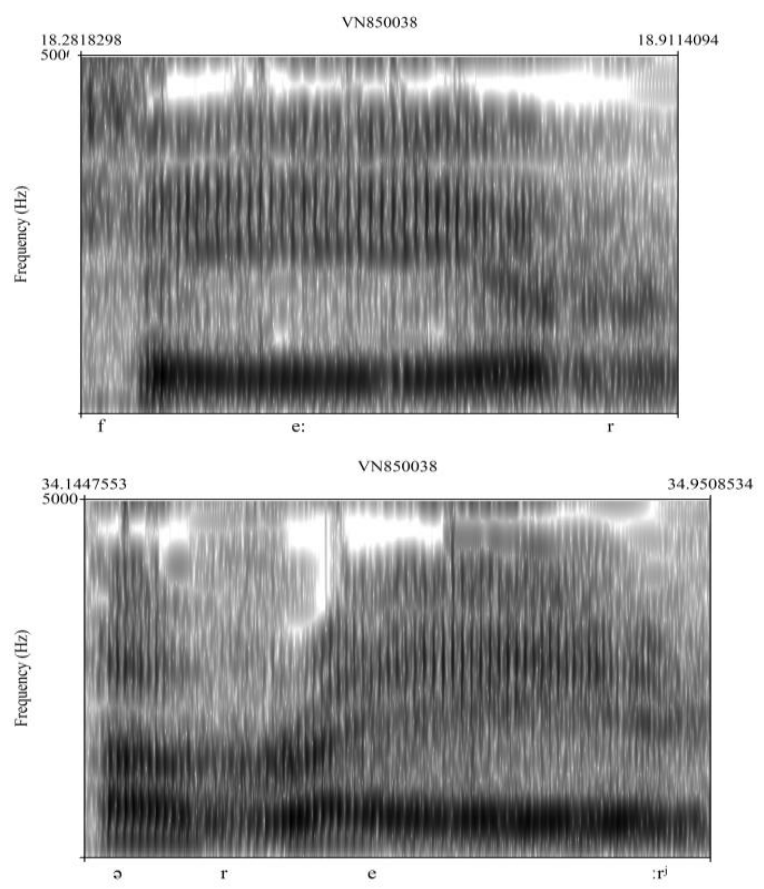

Figure 2. Féar and aréir pronounced in isolation by speaker P.

\footnotetext{
${ }^{10}$ A formant can be defined as a concentration of acoustic energy around a certain frequency. Although each vowel has several formants, phoneticians usually refer to the first two as the value of F1 determines whether a vowel is high or low, whereas the frequency of F2 tells us whether a vowel is front or back. In simple terms, the frequency of F1 is inversely proportional to the height of a vowel, while the greater the value of F2, the more advanced a vowel is.
} 
The finding has been confirmed by a statistical analysis performed for the purposes of the study. A T-test conducted for the purposes of the study proves that in the case of Speaker P the difference between the F1 values of vowels followed by $/ \mathrm{r} /$ and $/ \mathrm{r}^{\prime} /$ is statistically significant $(\mathrm{p}=2.08 \%)$.

However, in connected speech, the contrast is not consistently maintained and the differences between F1 values cannot be taken as evidence confirming the existence of a phonological contrast between $/ \mathrm{r} /$ and $/ \mathrm{r}^{\prime} /$. Figure 3 depicts the same two words as in Figure 2 produced by speaker $\mathrm{P}$ in connected speech and this time the vowel /e:/ is basically the same as far as its F1 is concerned.

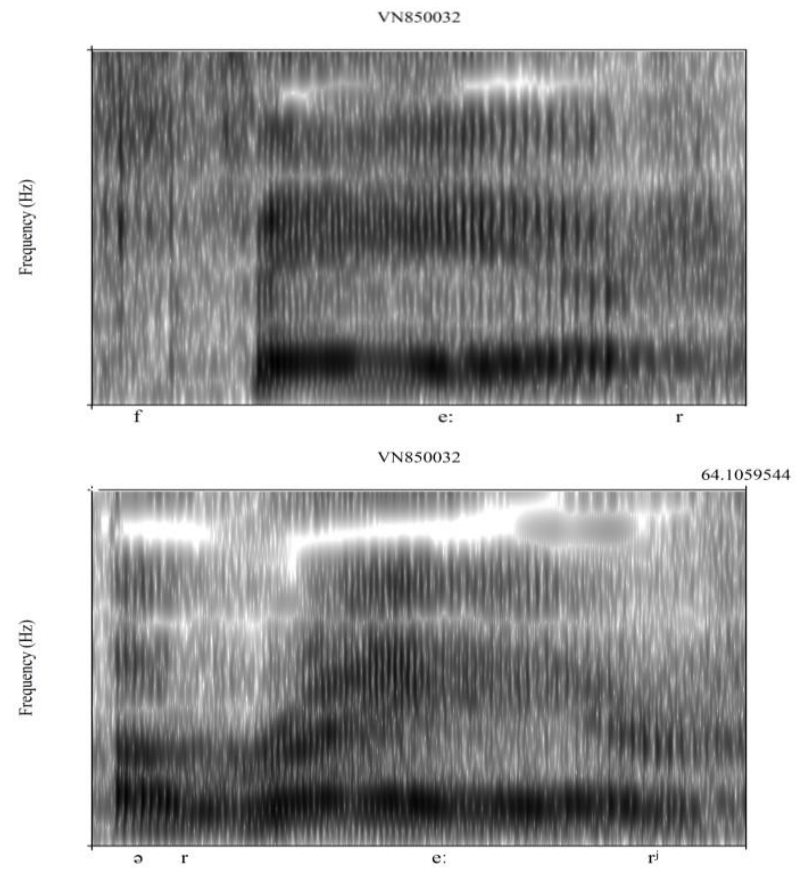

Figure 3. Féar and aréir pronounced in connected speech by speaker P.

Speaker M, who is native speaker of Connemara Irish, consistently makes a distinction between the two rhotics when pronounced in isolation. The spectrograms in Figure 2 above, which shows the words féar and aréir pronounced in isolation, provide evidence that, in the former, the vowel /e:/ is indeed considerably lower than in the latter $(665 \mathrm{~Hz}$ and $510 \mathrm{~Hz}$, respectively). This difference can be attributed to the raising of the tongue that was produced in anticipation of the following palatalised rhotic. In the case of Speaker M, 
the differences between F1 values of vowels preceding [r] and [r'] are highly significant as the $\mathrm{p}$ parameter appears to be lower than one per cent $(\mathrm{p}=$ $0.93 \%)$.

However, only occasionally does Speaker M produce the same type of contrast in connected speech. One such case is illustrated in Figure 3 where the vowel /e:/ in féar is almost as low as that pronounced in isolation (see the left panel of Figure 3), while the /e:/ sound of aréir is considerably lower and also unstable. At the onset, F1 has the value of $533 \mathrm{~Hz}$ and then it gradually decreases to $293 \mathrm{~Hz}$ at the offset. However, in many cases the differences between vowels followed by [r] and those followed by [r'] are minimal, if they exist at all. The finding is further confirmed by the statistics, as the $p$ parameter calculated for vowels in the two phonological contexts did not reach a statistically significant level, although it was relatively close to the 5\% threshold $(\mathrm{p}=5.27 \%)$.

\section{Rhotics in clusters}

\subsection{TR-clusters}

A TR-cluster is defined here as any cluster made up of an obstruent plus a rhotic. In BÉ $15 \%$ of all rhotics occur after an obstruent, though there appear to be clear distributional patterns both in terms of the localisation of the preceding obstruent and the broad-slender quality of the cluster. A majority of the initial TR-clusters in both DIL and BÉ are slender but there are significant differences correlated to the localisation of the obstruent. Generally speaking, clusters of a labial obstruent plus a rhotic tend to be slender, while clusters of a velar obstruent plus a rhotic tend to be broad. The following table (Table 2) illustrates this difference in both CD and DIL.

\begin{tabular}{|l|c|c|c|c|c|c|c|c|c|c|}
\hline localisation & \multicolumn{2}{|c|}{ CD broad } & \multicolumn{2}{c|}{ CD slender } & total & \multicolumn{2}{|c|}{ DIL broad } & \multicolumn{2}{c|}{ DIL slender } & total \\
\hline velar & 205 & $63.5 \%$ & 118 & $36.5 \%$ & 323 & 453 & $54.7 \%$ & 375 & $45.3 \%$ & 828 \\
\hline coronal & 177 & $61.5 \%$ & 111 & $38.5 \%$ & 288 & 407 & $44.4 \%$ & 509 & $55.6 \%$ & 916 \\
\hline labial & 158 & $44.9 \%$ & 194 & $55.1 \%$ & 352 & 521 & $35.3 \%$ & 644 & $64.7 \%$ & 996 \\
\hline total & 540 & $56.1 \%$ & 423 & $43.9 \%$ & 963 & 1381 & $47.5 \%$ & 1528 & $52.5 \%$ & 2909 \\
\hline
\end{tabular}

Table 2. Frequency of primary and secondary obstruent localisation in initial TRclusters in CD and DIL.

The figures from BÉ support the tendency of TR-clusters beginning with a labial to be slender and those with a velar to be broad and also agree with DIL in that there are more slender than broad TR-clusters beginning with a coronal.

In the speech of our two informants affrication affected initial clusters of a coronal obstruent plus a rhotic, especially when such clusters began with a 
coronal plosive. This phenomenon is illustrated in Figure 4, which shows the phrase trí rún as pronounced by Speaker $\mathrm{M}$ in connected speech. It can be clearly seen that the release of the $[\mathrm{t}]$ is followed by a period of strong friction, which is characteristic of affricates. The oscillogram in Figure 4 clearly shows that the resultant affricate is immediately followed by a full vowel and that the plosive and the rhotic have undergone affrication.

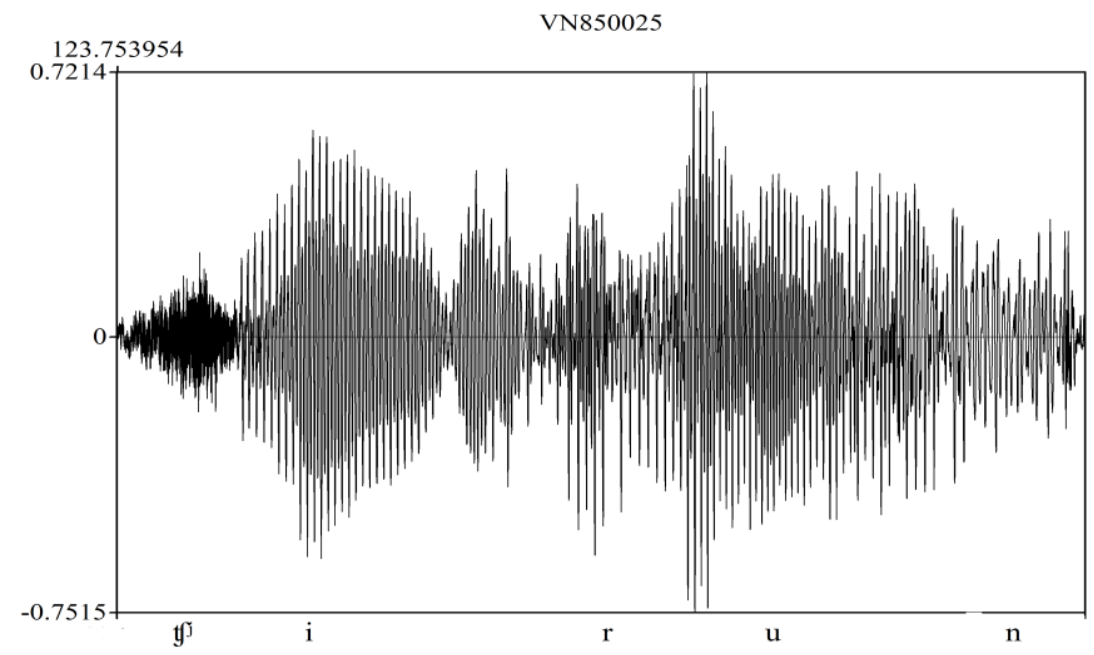

Figure 4. The affrication of a TR sound sequence in trí rún.

As Figure 5 shows, the initial plosive-rhotic cluster in Gréigis was realised with a distinct epenthetic vowel. However, one should not assume that the speaker made a pronunciation error, as acoustic analyses performed by many researchers have confirmed that such an 'intrusive' vocoid is usually found between consonant and a following rhotic (e.g. Recasens \& Espinosa 2007, Savu 2012, Baltazani \& Nikolaidis 2013). Interestingly, such intrusive vowels usually have distinct formants and their duration can be comparable to that of an unaccented vowel. In this case, the values of F1 $(530 \mathrm{~Hz})$ and F2 $(1468 \mathrm{~Hz})$ strongly suggest that it is a schwa-like sound (see Ladefoged \& Maddieson 1996) the duration of which $(56 \mathrm{~ms}$.) is $23 \mathrm{~ms}$. shorter than that of the unstressed [i] in the final syllable. 


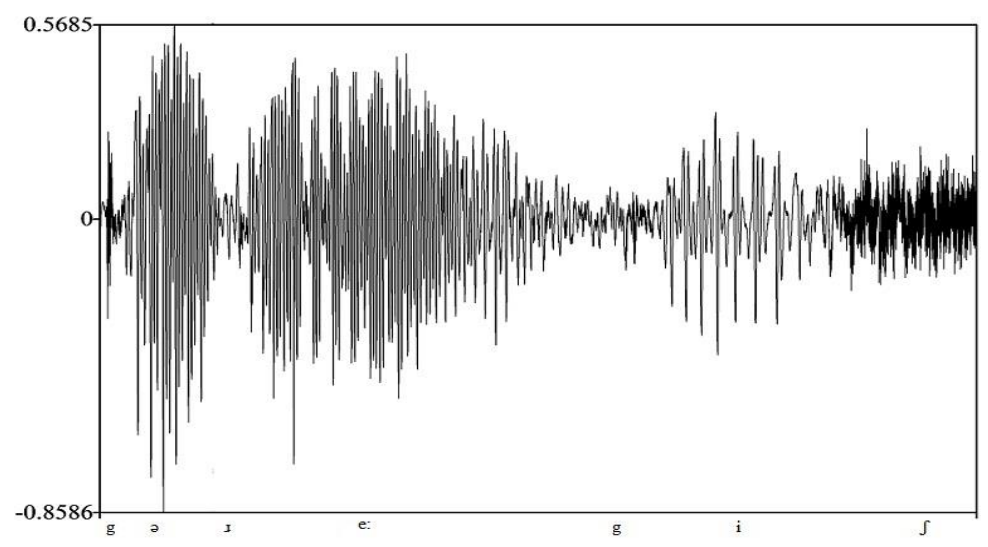

Figure 5. The token Gréigis in the speech of Speaker P.

\subsection{RT-clusters}

As regards RT-clusters, the overwhelming tendency is for them to occur after a short vowel. In RD, 93.9\% of all final clusters of rhotic plus obstruent occur after a short vowel. Furthermore, $64.8 \%$ of these RT-clusters are slender, a figure that is considerably higher than the proportion of slender rhotics in the language more broadly. Of the three localisations, coronal is unquestionably preferred to act as the second element of an RT-cluster involving a rhotic, comprising $68.3 \%$ of final rhotic plus plosive combinations in RD (378 tokens) and $73.5 \%$ of those in BÉ (611 tokens). In both corpora, clusters ending in $/ \mathrm{t} \mathrm{t}^{\prime} /$ were considerably more common than those ending $/ \mathrm{d} \mathrm{d}^{\prime} /$, but while the former tend to be slender (77.7\% in RD), the same tendency is not so clear for the latter (51\% in RD). The figures for BÉ are even higher: there are more than four times as many instances of $/ \mathrm{r}^{\prime} \mathrm{t}^{\prime} /$ as there are of $/ \mathrm{rt} /$ and only four instances of $/ \mathrm{r}^{\prime} \mathrm{d}^{\prime} /$, compared to $71 \mathrm{of} / \mathrm{rd} /$.

Phonetically, what differentiates the two types is the manner of articulation of the rhotic sound. In the former combinations, the rhotic is usually articulated as an approximant, while in the latter, the $/ \mathrm{r}^{\prime} /$ undergoes frication in $100 \%$ of cases. Figure 6, depicts the word bándearg [ba:ndia.əog] produced by Speaker M. The oscillogram shows clearly that in that token the rhotic sound is an approximant, as the first three formants are fairly distinct. As one would expect, there is an epenthetic vowel pronounced between the rhotic and the word-final $[\mathrm{g}]$, whose duration $(9.5 \mathrm{~ms}$.) is approximately half of that of the accented vowel in the same word. 


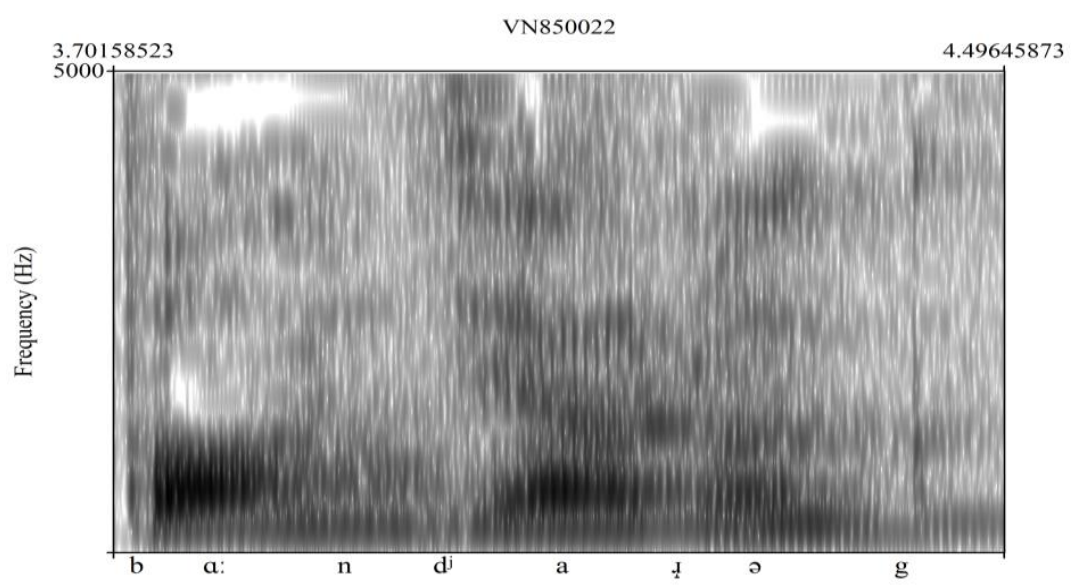

Figure 6. Approximant rhotic in bándearg.

As far as the F1 values of preceding vowels are concerned, in these two contexts, the obtained results suggest that the speakers do not consistently produce a higher vowel before $/ \mathbf{r}^{\prime} /$. For example, with regard to the near minimal pairs /-arC/ and /-ar' $\mathrm{C}^{\prime} /$ found in our corpus, the mean value of $\mathrm{F} 1$ was $603 \mathrm{~Hz}$ in the former context in the case of speaker P and $584 \mathrm{~Hz}$ in M's speech, whereas in the latter environment, where considerably lower F1 frequencies were expected, the means reached $613 \mathrm{~Hz}$ and $571 \mathrm{~Hz}$ respectively. Predictably, the differences are statistically insignificant as the p parameter is greater than $5 \%$.

Another interesting finding concerns word final /-rt/ and /-rd/ clusters. Although they are theoretically contrastive in that the second cluster contains a voiced plosive, in connected speech both speakers devoice the [d] sound. This conclusion is based on numerous realisations of the word bord, which constitutes an element of the carrier phrase. Importantly, the devoicing of [d] does not seem to be compensated for by lengthening the preceding vowel. For instance, in the near-minimal pair beart-bord, the vowel of the former lasts $16.4 \mathrm{~ms}$., while in the other word the vowel was, on average, $17.1 \mathrm{~ms}$. long in M's performance. By contrast, in Speaker P's speech, the mean duration of bord is $17.3 \mathrm{~ms}$. and it is $2 \mathrm{~ms}$. longer than that of beart. It should be borne in mind, however, that vowels found in the last syllable of a sentence undergo lengthening; therefore, given that the word bord occupies sentence final position in the carrier phrase, the results cannot be regarded as conclusive.

\section{Conclusions}

This paper has attempted to give an overview of the phonology and phonetics of rhotics in Modern Irish, drawing data from an acoustic analysis of the 
speech of two native speaker informants and from a number of corpora as well as secondary literature.

Despite the fact that the phonetic data presented in the study were obtained from only two participants, several interesting conclusions can be drawn. First and foremost, one can observe a very strong tendency towards the two rhotics being quite weak from the articulatory point of view, as very few trilled and tapped variants, which require the production of a full closure, were found in the data. The Irish sounds are predominantly approximants or fricatives. ${ }^{11}$ From a cross-linguistic perspective, there is a tendency for rhotics to weaken over time (see for example Blecua 2001 for Spanish, Jaworski \& Gillian 2011 for Polish). The results suggest that the phonological contrast between $/ \mathrm{r} /$ and $/ \mathrm{r}^{\prime} /$ is still maintained to a degree, but may be in danger of neutralisation in the future, as neither of the informants kept the two rhotics distinct in all contexts. Importantly, a similar sound change has been attested in a number of Slavic languages (Żygis 2005) in which the supposedly marked palatal rhotic has been either dropped or replaced.

Given that only two informants participated in the study, the results presented in the paper have to be treated with caution. We realise that in order to determine the phonological status of the two sounds, one has to collect a large amount of data from speakers of different ages and social backgrounds. As a consequence, the paper can only be regarded as a pilot study. However, a number of important lines of enquiry for further research have been identified by the current investigation.

Further research needs to be done to determine the status of the slender rhotic. While this study suggests that it is in danger of merging with its broad counterpart, a future study would ideally examine this question from a broader range of speakers. Additionally, the status of rhotics in clusters merits further investigation, particularly vowel epenthesis and affrication in TR-clusters and potential neutralisation in RT-clusters. The corpus data identified a number of interesting points regarding the frequency of Modern Irish rhotics, particularly their high overall frequency, relative rarity in initial position and various distributional anomalies in terms of the broad-slender distinction and the occurrence of preceding vowels. It is to be hoped that both the phonetic and corpus data presented in this paper will spur further research into the phonology and phonetics of Modern Irish and particularly its rhotic consonants.

\section{Cormac Anderson (Adam Mickiewicz University, Poznan, Poland) Sylwester Jaworski (Szczecin University, Poland)}

\footnotetext{
${ }^{11}$ The traditional dialect studies describe Irish rhotics as flaps or fricatives.
} 


\section{References}

Adams, G.B., 1970, 'Grammatical Analysis and Terminology in the Irish Bardic Schools', Folia Linguistica 4, 157-66.

Anderson, C., 2012, 'The Frequency of Irish Consonants: Bunreacht na hÉireann as a Case Study', in: Jaskuła, K., \& Malec, W., eds., Linguistic Meetings across Borders, Zamość: Państwowa Wyższa Skoła Zawodowa, 1124.

Anderson, C., 2014, 'Consonant Quality in Old Irish Revisited', in: Roma, E. and Stifter, D. eds., Selected Papers on Early Irish Language, Lewiston: Edwin Mellen Press.

Baltazani, M., Nikolaidis, K., 2013, 'The Many Faces of /r/', in: Spreafico, L., Vietti, A., eds., Rhotics. New Data and Perspectives, Bolzano: Bolzano University Press.

Bergin, O., 1916-55, 'Irish Grammatical Tracts', supplement to Ériu 8 (1916); 9 (1921/23); 10 (1926/28); 14 (1946); 17 (1955).

Blecua, B., 2001, Las vibrantes del Español: manifestaciones acusticas y procesos foneticos. $\mathrm{PhD}$ dissertation, Universidad Autonoma de Barcelona.

Bloch-Rozmej, A., 1998, Element Interactions in Phonology. A Study in Connemara Irish, Lublin: Redakcja Wydawnictw KUL.

Breatnach, R.B., 1947, The Irish of Ring, Co. Waterford: a Phonetic Study, Dublin: Dublin Institute for Advanced Studies.

Cyran, E., 1997, Resonance Elements in Phonology: A Study in Munster Irish, Lublin: Folium.

Cyran, E., 2002, Complexity Scales and Licensing Strength in Phonology, Lublin: Wydawnictwo KUL.

de Bhaldraithe, T., 1945, The Irish of Cois Fhairrge, Co. Galway: a Phonetic Study, Dublin: Dublin Institute for Advanced Studies.

de Búrca, S., 1958, The Irish of Tourmakeady, Co. Mayo: a Phonemic Study, Dublin: Dublin Institute for Advanced Studies.

de Búrca, S., 1960, 'Irish Phoneme Frequencies', Orbis 9:1, 464-70.

Doyle, A., Gussmann, E., 2004, A Reverse Dictionary of Modern Irish, Lublin: Folium.

Gleasure, J., 1968, 'Consonant Quality in Irish and a Problem of Segmentation', Studia Celtica 3, 79-87.

Greenberg, J., ed., 1966, Universals of Language, Cambridge, Ma: MIT Press. Gussmann, E., 1997, 'Putting your best foot forward. Stress in Munster Irish', in: Josephson, F., ed., Celts and Vikings. Proceedings of the Fourth Symposium of Societas Celtologica Nordica, Göteborg: Meijerbergs Institut, 103-33.

Jackson, K., 1960, 'Gemination and the Spirant Mutation', Celtica 5, 127-34. 
Jaskuła, K., 2006, Ancient Sound Changes and Old Irish Phonology, Lublin: Wydawnictwo KUL.

Jaworski, S., Gillian, E., 2011, 'On the Phonetic Instability of the Polish Rhotic /r/', Poznań Studies in Contemporary Linguistics 47(2), 380-98.

Kehrein, W., 2001, Phonological Representation and Phonetic Phasing Affricates and Laryngeals. PhD dissertation, University of Marburg.

Kim, C.-W., 1970, 'A Theory of Aspiration', Phonetica 21, 107-16.

Iosad, P., 2010, 'Right at the Left Edge: Initial Consonant Mutations in the Languages of the World', in: Cysouw, M., \& Wohlgemuth, J., eds., Rethinking Universals: How Rarities Affect Linguistic Theory, Berlin: Mouton de Gruyter, 105-38.

Iverson, G. K., Salmons, J. C., 1995, 'Aspiration and Laryngeal Representation in Germanic', Phonology 12, 369-96.

Ladefoged, P., Maddieson, I., 1996, The Sounds of the World's Languages, Oxford: Blackwell Publishers.

Lindau, M., 1985, 'The Story of $/ \mathrm{r} /$ ', in: Fromkin, V.A., ed., Phonetic Linguistics: Essays in Honor of Peter Ladefoged, New York: Academic Press, 157-68.

Lisker, L., Abramson, A. S., 1964, 'A Cross-Language Study of Voicing in Initial Stops: Acoustical Measurements', Word 20, 384-422.

Marstrander, C., 1932, 'Okklusiver og substrater', Norsk Tidskrift for Sprogvidenskap 5, 258-314.

Mac Mathúna, S., Ó Corráin, A., 1995, Collins Gem Irish Dictionary, Glasgow: Harper Collins.

McCone, K., 2005, A First Old Irish Grammar and Reader, including an Introduction to Middle Irish, Maynooth: Department of Old and Middle Irish.

Mhac an Fhailigh, É., 1968, The Irish of Erris, Co. Mayo: a Phonemic Study, Dublin: Dublin Institute for Advanced Studies.

Ní Chiosáin, M., 1994, 'Vowel Features and Radical Underspecification: Evidence from Irish', in: Dressler, W., \& Rennison, J., eds., Phonologica 1992. Proceedings of the 7th International Phonology Meeting, Torino: Rosenberg and Sellier, 157-64.

Ó Siadhail, M., 1989, Modern Irish: Grammatical Structure and Dialectical Variation, Cambridge: Cambridge University Press.

Ó Siadhail, M., Wigger, A., 1972, Córas fuaimeanna na Gaeilge [The Irish Sound System], Dublin: Dublin Institute of Advanced Studies.

Oftedal, M., 1962, 'A Morphemic Evaluation of the Celtic Initial Mutations', Lochlann 2, 93-102.

Pokorny, J., 1913, 'A Concise Old Irish Grammar', The Celtic Review 8:31, 267-88.

Quiggin, E. C., 1906, A Dialect of Donegal, Cambridge: Cambridge University Press. 
Quin, E. G. et al., eds., 2007, Dictionary of the Irish Language, Based Mainly on Old and Middle Irish Materials, Dublin: Royal Irish Academy.

Recasens, D., Espinosa, A., 2007, 'Phonetic Typology and Positional Allophones for Alveolar Rhotics in Catalan', Phonetica 63, 1-28.

Savu, C.F., 2012, 'An Acoustic-phonetic Perspective on the Phonological Behaviour of the Rhotic Tap', Proceedings of ConSOLE XX, 213-27.

Sommerfelt, A., 1954, 'Consonant Quantity in Celtic', Norsk Tidsskrift for Sprogvidenskap 17, 102-18.

Ternes, E., 1990, 'Initial Mutations in Celtic and West African Languages: Synchrony and Diachrony', Afrika und Übersee 73, 3-17.

Thurneysen, R., 1909, Handbuch des Alt-Irischen, Heidelberg: Carl Winter.

Thurneysen, R., 1946, A Grammar of Old Irish, Dublin: Dublin Institute of Advanced Studies.

Vendryes, J., 1908, Grammaire du Vieil-Irlandais: Phonétique, Morphologie, Syntaxe, Paris: E. Guilmoto.

Wagner, H., 1958-69, Linguistic Atlas and Survey of Irish Dialects, Dublin: Dublin Institute of Advanced Studies.

Wagner, H. 1959, Gaeilge Theilinn: foghraidheacht, gramadach, téacsanna [The Irish of Teilinn: Phonetics, Grammar, Texts], Dublin: Dublin Institute for Advanced Studies.

Żygis, M., 2005, '(Un)markedness of Trills: the Case of Slavic rpalatalisation', Zeitschrift für Slawistik 50, 383-407. 
